\title{
Religião e política no Brasil: violência legitimada
}

\author{
Religion and politics in Brazil: legitimate violence
}

Mariane Gonçalves Bento ${ }^{1}$

Resumo: A discussão política do Brasil atual encontra-se crivada de aspectos religiosos orbitando em seu redor. Não é uma dinâmica inédita; entretanto, carrega questões importantes de serem salientadas. Uma delas é a escalada de violência legitimada pela religião e vinculada às narrativas políticas. Este artigo trata, portanto, de uma revisão bibliográfica em que se pretende analisar a atuação religiosa no cenário político, hoje, com ênfase na ação dos evangélicos pentecostais e as possíveis reverberações desta atuação religiosa na sociedade e na política contemporânea por meio da organização desses grupos.

Palavras-chave: Religião. Política. Violência. Mídias.

Abstract: The political discussion in Brazil today is riddled with religious aspects orbiting around it. It is not an unprecedented dynamic, however, it carries important issues to be highlighted. One is the escalation of violence legitimized by religion and linked to political narratives. It is, therefore, a bibliographic review that intends to analyze the religious performance in the political scene today, with emphasis on the action of Pentecostal evangelicals and the possible reverberations of this religious performance in society and in contemporary politics through the organization of these groups.

Keywords: Religion. Politics. Violence. Media.

\section{Introdução}

O Brasil da atualidade nos mostra uma grande escalada de disputas narrativas entre adeptos de determinadas linhas políticas, o que acaba por resvalar em grupos religiosos que corroboram essas narrativas, acentuando as tensões. O presente trabalho busca traçar um mapa desta relação política religiosa contemporânea no Brasil e a escalada de violência promovida, muitas das vezes, por entes que compõem grupos religiosos cristãos. É flagrante a necessidade de pensar tais aspectos mediante os passos

\footnotetext{
${ }^{1}$ Graduada em História e especialista em Ciência da Religião pela UFJF. Professora de História da Rede Estadual de Minas Gerais. E-mail: marygoncalvesb@gmail.com
} 
que o país tem dado nesse sentido e a contribuição que esta análise pode dar à reflexão do papel da religião frente às questões políticas atuais. A proposta é refletir tais questões mediante escritos já produzidos pela comunidade acadêmica em torno das temáticas religião e política; conservadorismo; pentecostalismo; mídias e religião; violência e religião. Pretende-se, portanto, fazer uma revisão de contribuições acadêmicas a esse respeito, bem como uma análise autoral a partir desses índices temáticos tendo como questão-problema as seguintes perguntas: como os grupos políticos, balizados por discursos religiosos, violam atitudes e gestos religiosos transformando-os em ação política e violenta? De que modo a relação religião e política, sob influência das mídias, pode produzir violência?

A todo o momento somos bombardeados por acontecimentos e desdobramentos de âmbito político diante dos fatos e das notícias. Frente à escalada dicotômica que nos deparamos desde o impeachment da presidenta Dilma Rousseff em 2016, o posicionamento político de um grupo ou outro vem à baila, a fim de opor ou aglutinar pessoas e não faltam espaços de discussões sobre o tema, os quais também atingem a seara da religião. Essa influência, no entanto, pode ser uma definição inadequada mediante a inter-relação existente entre as esferas sociais, culturais e políticas que, juntas, formam um todo intrincado por diversos fatores. Nessa tônica, este trabalho busca, à luz da literatura existente sobre o tema, fazer uma análise do contexto atual em que a atuação religiosa de certos grupos e segmentos relacionam-se com a via política e, de igual modo, a política relaciona-se com grupos religiosos.

Objetiva-se, portanto, traçar uma linha de raciocínio que traga à tona um esboço do cenário político no que se relaciona com o religioso, sendo relevante destacar a guinada rumo a um posicionamento conservador e por vezes violento por parte de alguns indivíduos e grupos. Isso nos leva a construir a hipótese de que a religião é capaz de produzir violência em detrimento aos discursos de paz e fraternidade.

Embora a observação dessa aproximação entre religião, política e violência possa estar presente em distintas religiões, nossa análise direciona-se, principalmente, na via das igrejas neopentecostais que têm participado ativamente deste cenário, não sozinhas, mas com bastante preponderância. Aqui também se destaca o uso das mídias como ferramenta disseminadora de um discurso religioso atrelado a uma vertente política. Pelo alcance e força de seus emissários, acaba por surtir um efeito avassalador 
na sociedade brasileira, ligados às denominações religiosas ou a grupos que se veem representados por essas falas e, assim, encorajados a chancelar tais posicionamentos.

O trabalho está organizado em três partes. Na primeira, uma exposição conceitual envolvendo como religião e política se entrelaçam. Na segunda parte, uma abordagem da dinâmica de relacionamento entre o pentecostalismo e a ocupação do espaço público. Na terceira parte, o uso das mídias como propagadoras de pontos de vista sendo estes, muitas das vezes, carregados de aspectos violentos. Nesta via, estão em questão os grupos de dentro e também aqueles que orbitam por fora e fazem o aceite destes discursos. Assim sendo, buscam-se relacionar as variáveis aqui propostas de maneira a ser possível refletir criticamente e, um pouco mais, sobre essa crescente violência na sociedade brasileira diante da qual esta pesquisa se torna relevante e atual.

\section{Religião e política em discussão}

É comum que escutemos que certas coisas não se discutem. Quem nunca ouviu falar que religião, futebol e política não se discutem? Esta é uma grande falácia. Descontando as divergências possíveis entre o mundo futebolístico, falar de religião e política é fundamental tendo em vista as implicações destes temas em nosso cotidiano. Assim sendo, este artigo trata de aspectos inerentes a esta relação entre as esferas política e religiosa.

Desde a chegada dos portugueses às Terras de Santa Cruz que viriam a se tornar Brasil, temos o crivo das manifestações religiosas na história. A contar da primeira missa realizada logo que aqui chegaram, a vivência da religião (a princípio Cristã Católica) fez-se presente em nossa cultura em consonância com o mundo ocidental do século XVI em diante. O próprio avanço rumo às novas terras foi balizado, entre outros aspectos, pela busca de expansão da fé Católica. Assim, ocorreu a imposição da cultura e consequentemente da religião europeia sob o solo brasileiro. Esta direção, fincada na religião, atuou não somente na via dos costumes e práticas religiosas, mas também marcou instituições políticas e sociais ao longo do Brasil Colonial, estendendo-se ao Império e, claro, deixando como legado à República aspectos desta simbiose entre as instituições religiosas (destaque ao Catolicismo) e as instituições políticas e sociais do Brasil. 
Giumbelli (2008), procurando destacar de que modo se constitui a presença do religioso no espaço público, afirma que a instauração da República foi um grande marco em torno de um direcionamento à laicidade. Segundo ele, quando ocorreu um rompimento oficial com a Igreja Católica estabeleceu-se um ensino declarado leigo deixando-se de atrelar os registros civis aos registros eclesiais e modificando, inclusive, a instituição do casamento civil. Nesse sentido, o autor questiona em que medida os princípios de laicização foram concretizados no período, apontando que:

mais do que princípios, o que estão em jogo são dispositivos que configuram a relação entre Estado e religião dentro das exigências da laicidade, partindo-se da constatação de que esse modelo é adotado simultaneamente em muitas nações. Ou seja, temos muitos experimentos de laicidade naquele momento histórico e não precisamos, para entendê-los, sujeitar a maioria deles a um referencial analítico decalcado de alguma situação nacional particular (GIUMBELLI, 2008, p. 82).

Assim sendo, a perspectiva de laicização no Brasil ocorreu em meio a um contexto geral que já caminhava nesse sentido. Um ponto de reflexão a partir do século XIX foi a questão da secularização da sociedade, secularização esta que se esperava acontecer diante o avanço do tempo e o maior esclarecimento dos indivíduos mediante o qual seria possível perceber uma diminuição da adesão ao âmbito religioso que ficaria relegado à esfera privada, perdendo preponderância no espaço público. Entretanto, essa previsão não ocorreu tal qual o entendimento da comunidade acadêmica de fins do século XIX e início do XX. As fronteiras da religião ampliaram-se de modo a não ficar relegada somente ao privado, mas também a não se confundir com o público. São novas as fronteiras e não menos importantes.

Uma análise que pode ser trazida à tona é a de Bourdieu (1990) que, ao tratar da ampliação da fronteira da religião, apontou mudanças dos atores e da esfera religiosa contemporânea onde estas, entre outras, fazem "parte de um novo campo de lutas pela manipulação simbólica da condução da vida privada e a orientação da visão de mundo" (BOURDIEU, 1990, p. 121). Assim, a jornada referente ao que tange a religião assumiu novos contornos, evidenciando novas demandas de ação e condução não restritas ao campo da alma e da salvação. 
No que concerne aos aspectos históricos que envolvem essa vinculação entre religião e política, Burity (2001) aponta que, mais do que dizer se há ou houve tal relação tendo em vista que tal vínculo nunca se rompeu, faz-se necessário aferir se o padrão existente no ocidente consegue dar conta do que ele chama de deslocamento de fronteiras e ressignificação religiosa (BURITY, 2001). Assim, na medida em que se observa a trajetória de eventos ligados a movimentos religiosos, é que se tem de atentar para "uma configuração do religioso que opera, segundo uma lógica de deslocamento de fronteiras e ressignificação ou redescrição de práticas.” (BURITY, 2001, p. 28). Esta análise conduz para os caminhos diversos que a religião foi capaz de trilhar já que, apesar de haver contemporaneamente um movimento de aprofundamento da experiência religiosa pessoal, ocorreu também uma "desprivatização ou publicização do religioso" (BURITY, 2001, p. 28). É uma análise muito esclarecedora, pois mostra as várias possibilidades da religião não a colocando em caixas separadas do todo que a envolve, sendo, por isso, um tema complexo e fonte de muitos questionamentos e análises possíveis.

Não ocorre um desaparecimento da fronteira entre religioso e político; no entanto, também não há uma sobreposição de um sobre o outro. Burity (2001) define tal movimento como um deslocamento de fronteiras que implica numa atuação e regulação maior do Estado em áreas antes consideradas privadas na ampliação da oferta e competição religiosa, assim como nas representações políticas que outrora eram relegadas apenas ao âmbito privado e que agora aparecem como um problema político a ser sanado.

Pois é notório que para além das reafirmações permitidas pela linguagem da "volta da religião" ou da "ampliação da esfera pública ou política", o que se passa é uma mudança na definição do que seja política ou religião. De um lado, os limites do político extrapolam o estado, o que atesta a insuficiência do neutralismo e da separação entre igreja e estado para disciplinar a relação religião/política. De outro lado, há uma visível desinstitucionalização da religião, que se traduz na proliferação de igrejas, movimentos e grupos informais, que não mais se prendem aos protocolos de autorização ou sanção eclesiástica, bem como na difusão/disseminação do religioso para além das fronteiras reguladas pelas instituições religiosas (BURITY, 2001, p. 34). 
A partir desse referencial de deslocamento de fronteiras da religião em uma conceituação ampla do que representaria "a religião" neste texto, nas etapas que se seguem buscarei refletir, considerando nosso recorte temático, a atuação do pentecostalismo no meio público e as implicações dessa atuação no Brasil.

\section{Espaço público e pentecostalismo}

O Brasil experienciou uma grande movimentação em relação à sociedade civil no que concerne à busca de direitos e voz frente à governabilidade autoritária, engendrada desde 1964 em solo brasileiro, e que pela força de vários fatores vieram a ruir em meados da década de 1980. Nessa via, o que é importante frisar é quão fundamental foram os questionamentos dos movimentos sociais frente à estrutura política vigente. Nesta busca, traz-se à tona o desejo de ocupação do espaço público e de um olhar mais apurado para as demandas não contempladas pelo Estado. Esse movimento acaba por fazer emergir novos atores no cenário político sendo os grupos religiosos um deles.

A politização do discurso religioso nunca foi uma marca apenas deste período em questão, a exemplo da romanização do catolicismo, as repúblicas latino-americanas, a teologia da libertação, entre outros (BURITY, 2016). Entretanto, a partir dos anos 1990, observa-se uma movimentação que traz "para o primeiro plano o discurso político pentecostal” (BURITY, 2016, p. 27). O alvorecer do discurso político pentecostal é definido como uma expressão de religião pública na qual as práticas religiosas não se conteriam na fronteira do privado, projetando-se pelo espaço público como discurso de valores, cultura e ação coletiva (BURITY, 2016). As características que fizeram o perfil pentecostal pós 1980 tornar-se uma religião pública são a demanda por participação nas instituições representativas, a publicização alcançada para além da política, tocando também a cultura de massas (jornais, gravadoras, tevê, rádio etc.). Assim, a religião passou a tratar detidamente da política profissionalizando sua atuação, sobretudo com "a utilização deliberada de sua própria linguagem teológica como registro legítimo de argumentação política" (BURITY, 2016, p. 37-38).

Nesse movimento, a exposição pentecostal alcançada foi imensa e, a partir de então, inseriu-se nas discussões sociais e politizou todos os temas que versassem sobre 
algum aspecto da fé deste grupo. Desse modo, a definição mais adequada seria de uma religião pública e não uma religião no espaço público (BURITY, 2016).

Em outras palavras, a religião pública ao mesmo tempo impele "a religião" para o que já não se contém ou regula pela jurisdição organizacional ou simbólica do mundo religioso, e posiciona relacionalmente a identidade religiosa de tal forma que o "nãoreligioso" tanto quanto o "outro religioso" passam a interferir permanentemente na vivência e no estar-em-casa da identidade religiosa. Esse problema de definição da fronteira ou, antes, da crescente porosidade da fronteira entre o religioso e o secular atinge a religião pública de duas formas: porque ela ultrapassa fronteiras, levando o religioso para dentro do secular, por assim dizer; e porque ela não pode erigir fronteiras impenetráveis à lógica secular no seu próprio interior (BURITY, 2016, p. 40).

À luz da reflexão de Burity sobre o enquadramento do pentecostalismo brasileiro como religião pública, no próximo tópico descreveremos a atuação religiosa dos adeptos desta vertente de um modo mais específico, relacionando-a à mídia e à violência, demarcando de que forma se procedeu esta atuação, tal como questionado na introdução desta pesquisa, o que será abordado brevemente na próxima seção.

\section{Evangélicos, mídias e violências: o "Eu" e o "Outro"}

Rodrigues e Gouvêa (2020) no texto "Pentecostalismo, política e conservadorismo" buscaram compreender como os discursos religiosos de grupos pentecostalizados influenciaram a política nacional atual, perspectiva sob a qual estará ancorada nossa linha de raciocínio. Para tanto, uma importante noção a partir daqui é a conceituação feita pelos autores a qual nos orienta a pensar sobre o termo "evangélico":

No Brasil, esse termo tem sido usado de modo generalista para indicar uma pessoa ou grupo de pessoas que declaram ser cristãos e seguirem a Bíblia, desde a literatura do Antigo Testamento até as referências do Novo Testamento, que contam a vida e os ensinos de Jesus Cristo, assim como as origens do movimento cristão que deu origem às igrejas institucionalizadas católicas. Os evangélicos, embora cristãos, não são católicos, mas derivam de Protestantes (do século 16) e Pentecostais (dos séculos 19 e 20), alguns dos quais se caracterizam por interpretarem literalmente os textos bíblicos, baseados nas doutrinas da inerrância e da infalibilidade bíblica (RODRIGUES; GOUVÊA, 2020, p. 38). 
Nessa dinâmica, a caracterização de evangélico traz à tona um grupo religioso que atua no universo brasileiro de maneira a balizar suas ações e modos de vida a partir de uma leitura bíblica específica, e que reverbera na sociedade como preocupação com os hábitos e formas de agir dos indivíduos, instituindo, assim, regras de conduta. Nessa via, o conservadorismo ganha corpo, pensando-se aqui, conservadorismo como prática que envolve manter ideias e formas de agir que seriam mais adequadas a determinado grupo.

Frente a isso, o "eu” evangélico supõe-se guardião dos bons costumes sociais e emana tal ponto de vista pela sociedade de modo a fazer com que todo aquele que não está investido do mesmo pensamento, o "outro", seja atingido por seu discurso. A leitura e interpretação dos textos bíblicos são amplamente disseminadas a fim de proporcionar uma dinâmica de mediação entre o divino representado por aqueles que seguem as premissas de Deus (os escolhidos) e os que não se enquadrariam neste grupo.

As noções de "povo escolhido" e "geração eleita" derivam da apropriação de textos bíblicos do Antigo Testamento (AT). Segundo essas referências, Iahweh - Deus criador dos céus e da terra- escolheu Israel como seu povo, eleito entre todos os outros povos, para reinar sobre a terra. Portanto, esse povo, assim como seus herdeiros nas gerações seguintes, seria o povo exclusivo de Deus e sob essa inscrição teria a exclusividade da salvação. Todos os outros povos que se curvassem diante essa condição seriam igualmente abençoados (RODRIGUES; GOUVÊA, 2020, p. 41).

Assim sendo, a presença dos evangélicos como religião pública, no Brasil, corroboraria a lógica de disseminação da "verdade" e atuaria fortemente na estruturação de uma política "supremacista, hierárquica e violenta (beligerante)" (RODRIGUES; GOUVÊA, 2020, p. 45), de modo que os grupos políticos balizados por discursos religiosos estariam violando atitudes e gestos religiosos, transformando-os em ação política e violenta.

Em outras palavras, em nome da fé e da moral evangélica (baseada, especialmente, na antiga aliança entre Deus e o povo hebreu), lideranças pentecostais ao ocuparem espaços públicos e políticos com seus discursos, em geral, têm se baseado em certa tradição de seleção e interpretação bíblica (literalista), cuja moral separa: o certo do errado, o bem do mal, o papel do homem do papel da mulher, o lugar 
dos filhos da luz em relação aos filhos das trevas, cristãos dos não cristãos, dos legitimamente livres (porque convertidos) em relação aos escravos (porque adoradores de outras divindades), dos donos da terra daqueles que trabalham nela e, finalmente, dos exploradores em relação aos explorados (RODRIGUES; GOUVÊA, 2020, p. 45).

Sintomático desse movimento é a escalada de uma linguagem de violência emanada por partícipes e lideranças de grupos religiosos em sua maioria evangélica. Em nome da fé e dos costumes que estes julgam ser mais adequados, a discussão se acirra e reflete uma visão tomada por caracteres não tão afáveis. Em nome de Deus, percebe-se a legitimação de violências para com grupos considerados um problema para a fé Cristã mais uma vez na história do Brasil. Esta violência não é uma novidade, entretanto, o que há de se perceber é que a narrativa política é direcionada à comunidade cristã evangélica de modo a evidenciar a necessidade de diferenciar-se daqueles que não são considerados fiéis. Os grupos religiosos, por sua vez, alimentam-se deste discurso para se fortalecer como grupo político religioso, o ciclo é mantido e, assim, acontece uma aliança "perfeita", mesmo que às custas de mazelas daqueles que não estão de acordo com a narrativa política religiosa beligerante do contexto atual do Brasil.

Essa atitude muito tem a ver com a própria estrutura dos escritos religiosos que balizam o pensamento cristão evangélico brasileiro. Rodrigues (2019), ao tratar de aspectos ligados a uma linguagem que faz referência à violência e de algum modo a justifica, aponta o quão ligado está o sagrado à violência e demandaria uma ritualística também violenta. A Bíblia, portanto, traz aspectos que baseiam essa atitude voltada às violências.

\footnotetext{
Atos de violência concretizados em guerras, assassinatos, tramas, golpes, exércitos, entre outros, emergem da literatura bíblica como atitudes religiosas combativas que nos permitem afirmar que as religiões também se definem pelo termo violência. Em especial, as que derivam do tronco abraâmico (RODRIGUES, 2019, p. 77).
}

Assim, engendra-se uma lógica de que "todos os que não estão sob a fé em Deus estariam sob o comando do Diabo, portanto seriam os inimigos de Deus e de seu povo" (RODRIGUES, 2019, p. 73) e nesta via, a luta seria legítima. Estes inimigos são identificáveis em falas contrárias aos gays, participantes de religiões não cristãs, pessoas que não seguem uma vida ortodoxa, por exemplo. No Brasil, o atual governo liderado 
pelo Presidente Jair Messias Bolsonaro, atua nestas frentes, alimentando a beligerância. Suas falas ríspidas que desrespeitam a pluralidade, ganham apoio desses grupos ao mesmo tempo em que apoia o discurso de muitos deles, sendo importante nesta guinada conservadora que, por vezes, legitima a violência contra os entes da república "não fiéis".

Seguindo por outra linha de raciocínio, tem-se a reflexão interessante quanto à eleição do chamado "bode expiatório". Isso é abordado por Renê Girard na obra $A$ Violência e o Sagrado (GIRARD, 1972), também analisado por Sbardella e Peretti (2019). O ponto de interseção está na abordagem da violência na religião e por isso cabe mencioná-lo. Aqui se expõe um ponto de vista que coloca a necessidade de apontar-se alguém ou algo para dirimir os males que recaíam sobre a comunidade, sem, no entanto, fazer da religião uma colaboradora da violência. Os autores, balizados pela obra de Girard, traçam elementos importantes quanto a esta linha de pensamento explicitando a questão do bode expiatório que seria uma "vítima escolhida para o sacrifício, aquele sobre o qual recai toda a culpa da desagregação do grupo, de um mal que sobrevém à comunidade" (SBARDELLA; PERETTI, 2019, p. 51).

Nessa análise, a ação violenta atuaria como uma denúncia dos males sociais e, como o autor analisa, as regulações seriam necessárias para que a sociedade se atentasse aos problemas que ela mesma causa, sendo universal o fato de "que pessoas ou grupo de pessoas estão sujeitos a ser vítimas, bodes expiatórios de suas próprias sociedades" (SBARDELLA; PERETTI, 2019, p. 57). Trazendo para nosso foco de análise, o discurso beligerante elegeria o "bom cristão" como sendo a vítima da sociedade que não segue os ditames das escrituras e que, portanto, sacrifica-se na luta por uma nação em que o lema tenha "Deus acima de todos". A violência seria, pois, denunciada por meio dos vários veículos e espaços (inclusive o político) e por isso a luta contra os algozes se faria necessária.

De todo modo, não se pode negar quão atrelado à religião cristã está o tema da violência. Em se tratando do Brasil atual, muitas falas e ações resvalam nas minorias causando ações intolerantes de toda sorte, reforçadas por vários veículos midiáticos de disseminação de informações, grandes responsáveis pelo alargamento do espaço ocupado pela religião e política. Cunha (2016), que busca descrever e interpretar a maior ocupação de espaço pelos evangélicos na política partidária e como as grandes 
mídias tratam a questão política, aponta que o neoconservadorismo evangélico faria parte de um contexto de fortalecimento conservador na esfera pública brasileira em geral. E aqui, portanto, temos outro ponto relevante na análise que é o fato de os valores de direita (mais conservadores) obter simpatia de uma grande parcela de brasileiros.

Frente a isso, lideranças evangélicas e políticos conservadores não ligados às igrejas evangélicas, mas que se ancoram nelas, emergem pautas conservadoras ganhando grande apoio eleitoral nacional (CUNHA, 2016). Tal apoio não ocorre somente pela força da representatividade evangélica na política ou pelo uso político de assuntos ligados à moral cristã, mas também por todo um contexto de apropriação dessas pautas na sociedade como um todo.

Com discursos dentro do ideário da moral cristã (contra o aborto e o controle da natalidade, e a favor da assistência psicológica a homossexuais, como se a opção sexual fosse uma doença a ser tratada) aliado a princípios caros ao liberalismo na política e na economia (Estado mínimo e elogios ao livre mercado), essas personagens têm captado apoios para além do círculo religioso. Na visão destas lideranças, a família está sob a ameaça dos movimentos civis de gênero e enfrentamento da violência sexual, reforçados pela abertura a estas demandas no campo político, intensificada a partir de 2002 (CUNHA, 2016, p. 153).

A análise aqui apresentada aponta que tal escalada conservadora muito tem a ver com as características da própria sociedade brasileira, e que é acentuada pelo processo de midiatização que a religião e a política do Brasil, hoje, passam na construção de bandeiras preconceituosas e estereotipadas, distorcendo entendimentos que, junto às ciências, aos benefícios tecnológicos e às garantias do direito democrático, foram conquistados ao longo da história brasileira. Ademais, a postura conservadora da aliança entre religião e política exacerbada pela mídia atende aos ideais capitalistas, tal como confere Cunha:

Nesse caso, a lógica produtiva das mídias, baseada na espetacularização, é assumida pela religião e pela política em intercâmbio. Este intercâmbio dá-se também no terreno da ideologia, marcada pelo conservadorismo religioso e midiático, ocorrendo o que Max Weber nominou "afinidades eletivas". Segundo Weber, para a consolidação do capitalismo foi fundamental o intercâmbio deste com a cultura religiosa protestante puritana de matriz calvinista. Isto foi possível pelo fato de o protestantismo possuir afinidades (simpatia, 


\section{SACRILEGENS

similaridades) eletivas (escolhas) com o capitalismo (CUNHA, 2016, p. 157).

Cunha evidencia a atuação dos evangélicos como bloco articulado que desenvolve cultura de massas e se faz presente em vários âmbitos da vida do indivíduo. Seus discursos políticos religiosos são bem aceitos por parcelas ligadas, ou não, a uma denominação religiosa e o êxito acaba sendo bastante impulsionado pela força das mídias. Comportando-se como segmento governista, os evangélicos articulam-se em apoiar candidatos com reais chances de vencer eleições e fazem também acordos em prol de sua denominação religiosa (GONÇALVES, 2010), sendo, então, parte importante no cenário político nacional atual. Nesse aspecto, atentamo-nos para um cenário político crivado de dicotomias que se acentuam cada dia que passa. $\mathrm{O}$ discurso religioso conservador, em muito, colabora para este clima, delineando esse contexto beligerante que enfrentamos intensificado em meio ao momento de crise de saúde em razão da pandemia da Covid-19. Pieper e Mendes (2020) retomam um pouco dessa reflexão mediante o conceito de necropolítica, apontando que:

um traço básico da necropolítica é esse laço de inimizade. Basicamente, a ideia é a criação fantasiosa de um inimigo que pelo próprio fato de existir ameaça o "nós" e, portanto, deve ser eliminado. Isso faz com que o ódio e o ressentimento criem vínculos entre as pessoas. E esse mesmo ódio contamina todo esse sistema (PIEPER; MENDES, 2020, p. 23).

A violência e a morte ganham contornos diferentes numa política que faz do outro um inimigo a ser combatido por não apresentar um ideário político religioso similar ao do seu grupo. Os laços de inimizade, evidenciados pelos autores, são absorvidos também pelo discurso político religioso evangélico sendo sintomática a aversão a tudo que não faz parte da cobertura narrativa cristã pentecostal.

Por fim, cabe enfatizar que temos um sistema político que acaba por contribuir para o fenômeno da ascensão de políticos religiosos. E nesta fragilidade, como os eleitores escolhem seus candidatos através de qualidades pessoais, largam na frente bispos e pastores (GONÇALVES, 2010). Nessa ótica, é tempo de reflexão e ajuste. Tendo no horizonte o momento delicado em que vivemos, não podemos deixar escapar a oportunidade de repensar a atuação dos grupos religiosos, sejam eles evangélicos 
institucionalizados ou não, na vida política do Brasil, bem como as implicações que esta guinada pode trazer, positiva ou negativamente, para o meio social e político.

\section{Considerações Finais}

Por força do debate acalorado já existente no âmbito político e social do Brasil mediante as alternativas de projeto de país que se aventa, o tema religião e política foram aqui abordados a fim de contribuir, de algum modo, para uma reflexão possível diante de tantos atores e discursos disponíveis. Desse modo, buscou-se trazer à tona autores que já trabalham com o assunto para fazer emergir alguns pontos importantes de suas análises e estender a reflexão a partir dos mesmos.

A atuação religiosa na política arrebanha muitas pessoas e, ao conter um discurso que traz em si violências contra outros grupos, apresenta uma problemática muito grande. $\mathrm{Na}$ necessidade de apontar aqueles que não cumprem uma cartilha específica de vida e fé, lança-se mão de um posicionamento intolerante com aqueles que não colaboram a uma perspectiva cristã evangélica conservadora. Os agentes políticos eleitos sob o apoio de uma base religiosa evangélica ou simpática a ela, ao expor posicionamentos ligados a esta moral acabam por responder a seu grupo, mas também trazem implicações à sociedade como um todo no que tange a uma perspectiva de conflito. As mídias sociais colaboram muito neste sentido, pois sustentam discursos religiosos atrelados à política e discursos políticos atrelados à religião numa integração poderosamente influenciadora.

Conduzir uma discussão tão importante e tão complexa demanda-se um maior aprofundamento, o que ainda haverá ocasião para desenvolver. Todavia, a meu ver, é preciso pensar que o limite entre o âmbito religioso e o político, de modo geral, foi alargado e modificado contemporaneamente, e fez surtir uma vivência de religião pública por parte do pentecostalismo. Esta guinada, diante de uma busca por representatividade no cenário político, desembocou em uma atuação intensa por parte destes grupos religiosos, e também de políticos atrelados a eles reverberando social e politicamente na forma de debate, discussões e produção de conteúdo midiático a fim de arrebanhar simpatizantes à sua forma de pensamento. 
Referências Bibliográficas

BOURDIEU, Pierre. A dissolução do religioso. In: Coisas Ditas. São Paulo:

Brasiliense, 1990, p. 119-125. Disponível em:

https://nepegeo.paginas.ufsc.br/files/2018/06/BOURDIEU-Pierre.-Coisas-ditas.pdf .

Acesso em: 27 abr. 2021.

BURITY, Joanildo. Religião e política na fronteira: desinstitucionalização e deslocamento numa relação historicamente polêmica. São Paulo: Revista de Estudos da Religião, n. 4, 2001, p. 27-45. Disponível em:

https://www.pucsp.br/rever/rv4_2001/p_burity.pdf. Acesso em: 27 abr. 2021.

BURITY, Joanildo. Religião, cultura e espaço público: onde estamos na presente conjuntura? (Org.). MEZZOMO, F.; PÁTARO, C.; HAHN, F. In: Religião, cultura e espaço público. São Paulo: Olho D’água; Campo Mourão: Ed. Fecilcam, 2016, p. $13-$ 49. Disponível em:

https://www.researchgate.net/publication/299523225_Religiao_cultura_e_espaco_publi co_onde_estamos_na_presente_conjuntura . Acesso em: 27 abr. 2021.

CUNHA, Magali do Nascimento. Religião e Política: ressonâncias do neoconservadorismo evangélico nas mídias brasileiras. Perseu: Revista do Centro Sérgio Buarque de Holanda da Fundação Perseu Abramo. nº 11, Ano 7, 2016.

Disponível em:https://revistaperseu.fpabramo.org.br/index.php/revistaperseu/article/view/112/80. Acesso em: 27 abr. 2021.

GIUMBELLI, Emerson. A presença do religioso no espaço público: modalidades no Brasil. Relig. soc. [online], vol. 28, n.2, 2008, p.80-101. Disponível em: https://www.scielo.br/scielo.php?script=sci_arttext\&pid=S0100-85872008000200005 . Acesso em: 27 abr. 2021.

GONÇALVES, R. B. Religião e representação política: a presença evangélica na disputa eleitoral brasileira. Revista Espaço Acadêmico, 10(116), 2010, p. 13-20. Disponível em: http://periodicos.uem.br/ojs/index.php/EspacoAcademico/article/download/10891/6468/ 0 . Acesso em: 27 abr. 2021.

PIEPER, F.; MENDES, D. Religião e Necropolítica. (Org.) PIEPER, Frederico; MENDES, Danilo In: Religião em tempos de crise. São Bernardo do Campo: Ambigrama, 2020. Disponível em: https://www2.ufjf.br/ppcir/wpcontent/uploads/sites/145/2020/09/Religiao_em_tempos_de_Crise-livro-final.pdf . Acesso em: 27 abr. 2021.

RODRIGUES, E.; GOUVÊA, A. Pentecostalismo, Política e Conservadorismo. (Orgs.) PIEPER, Frederico; MENDES, Danilo, In: Religião em tempos de crise. São Bernardo do Campo: Ambigrama, 2020. Disponível em: https://www2.ufjf.br/ppcir/wpcontent/uploads/sites/145/2020/09/Religiao_em_tempos_de_Crise-livro-final.pdf . Acesso em: 27 abr. 2021. 
RODRIGUES, Elisa. Religião e violência: uma leitura fenomenológica. Estudos Teológicos (Online), v. 59, 2019, p. 61-79. Disponível em:

http://periodicos.est.edu.br/index.php/estudos_teologicos/article/view/3615. Acesso em: 27 abr. 2021.

SBARDELlA, E. L; PERETTI, C. Cristianismo e violência. Contribuições teológicas a partir de René Girard. Estudos Teológicos, v.59, n. 1. 2019, p. 47-60. Disponível em:

http://periodicos.est.edu.br/index.php/estudos_teologicos/article/view/3617. Acesso em: 27 abr. 2021. 